\title{
Awareness Of Medical Students Regarding Periodontal Disease In Diabetic Patients In A Private Dental College of Karachi
}

\author{
Natasha Fatima, Saima Mazhar, Mushtaq Ahmed, Umair Aslam
}

\begin{abstract}
:
Objective: The aim of this study was to evaluate the awareness and knowledge of periodontal disease among medical students of Bahria University Medical and Dental College (BUMDC) while treating diabetic patients.
\end{abstract}

Study design and Setting: It was a cross sectional study conducted in Bahria University Medical and Dental College (BUMDC) Karachi.

Methodology: This study included participants currently studying in $3^{\text {rd }}, 4^{\text {th }}$ and final year Bachelor of Medicine and Bachelor of Surgery (MBBS) in BUMDC Karachi. Questionnaire was divided into two parts, in the first part, demographic details and year of study were asked, in the second part, questions regarding diabetes mellitus and its complications were included. Total of 384 participants participated in the study and the data was statistically analyzed using responses SPSS version 23.

Results: All the participants successfully completed the questionnaire so the response rate was $100 \%$ in this study. From 384 participants, $37 \%$ were male and $63 \%$ were female. The majority of the students were aged between $22-23$ years. About $64.1 \%$ of respondents thought that they were aware of periodontal disease in diabetic patients whereas only $19.5 \%$ individual had knowledge of periodontitis. Also around $44 \%$ of medical students could not specify clinical manifestations in periodontitis and only $48.4 \%$ participants could state the periodontal manifestations present in diabetic mellitus.

Conclusion: It is concluded from the study that medical students have very limited knowledge regarding periodontal disease and its association with diabetes mellitus. Very few medical students were informed about referring the diabetic patients to the dental surgeon.

Keywords: Diabetes Mellitus, Medical Students, Periodontitis, Periodontal Disease.

\section{INTRODUCTION:}

Diabetes is a metabolic disorder in which glucose level increases, with functional disorders of metabolism of protein, fat and carbohydrate, which results from defects in insulin secretion, insulin action, or both. ${ }^{1}$ Diabetes has been graded into multiple categories including, Type 1 diabetes (caused by autoimmune â-cell destruction, which leads to complete deficiency of insulin ), Type 2 diabetes (caused by loss of â-cell insulin secretion progressively which eventually causes insulin resistance), Gestational diabetes mellitus (GDM) (occurs in pregnancy mainly $2^{\text {nd }}$ and $3^{\text {rd }}$ trimester), Specific types of diabetes due to other causes, e.g., monogenic

I Natasha Fatima

Registrar

Bahria University Medical and Dental College, Karachi

I Email: natashafatima93@yahoo.com

I

Saima Mazhar

Sr. Lecturer

I Bahria University Medical and Dental College, Karachi

I Mushtaq Ahmed

I Sr. Associate Professor

I Bahria University Medical and Dental College, Karachi

I Umair Aslam

Lecturer

Bahria University Medical and Dental College, Karachi

Received: 23-05-2019

I Accepted. 11-09-2019 diabetes syndromes (neonatal diabetes and maturity-onset diabetes of the young (MODY), diseases of the exocrine pancreas (cystic fibrosis), and drug- or chemical-induced diabetes (with glucocorticoid use, in the treatment of HIV/AIDS, or after organ transplantation). ${ }^{2}$ Diabetes mellitus can cause multiple complications e.g. cardiac arrest, brain stroke, renal failure, leg amputation, loss of vision and nerve damage. In pregnancy, poorly controlled diabetes increases the risk of fetal death and other complications. ${ }^{3}$

In 2017 International Diabetes Federation (IDF) reported that around 451 million (age 18-99?years) people are affected with diabetes worldwide, which may increase up to 693 million by 2045 . It was estimated that $49.7 \%$ diabetic individuals are never diagnosed. Around 5 million people, in the age range of 20-99 years, died because of diabetes worldwide. ${ }^{4}$ The demographical studies showed that the prevalence of Diabetes in Pakistan is ranging from $7.6 \%$ to $11 \% .^{5}$ The prevalence of DM in Pakistan was reported to be 5.2 million in the year 2000 and by the year 2030 , it may reach up to 13.9 million. ${ }^{6}$

Among other systemic complication, diabetes played an important role in oral diseases. Individuals with poorly controlled diabetes are more vulnerable to oral infections. Periodontitis is a sixth complication of diabetes. ${ }^{7}$ Periodontitis is a condition which causes inflammatory changes in the supporting structures of the teeth including gingival fibers, 
bone and periodontal fibers, which can eventually lead to loss of teeth and may cause systemic inflammation. Chronic periodontitis mostly occurs in adults whereas aggressive periodontitis affects children only. ${ }^{8}$ According to American Dental Association (ADA), individuals with fasting blood glucose levels higher than $125 \mathrm{mg} / \mathrm{dL}$ or $7 \mathrm{mmol} / \mathrm{L}$ are considered as diabetic. ${ }^{8}$

Diagnosis is made on the basis of systemic and oral signs and symptoms. Systemic signs and Symptoms include hyperglycemia include polyuria, polydipsia, weight loss, sometimes with polyphagia, and blurred vision whereas oral symptoms include gingivitis and periodontitis, recurrent oral fungal infections and impaired wound healing with reduced salivary flow. ${ }^{9}$ Diabetes attack all periodontal factors, including bleeding on probing, probing depths, attachment loss and tooth loss. ${ }^{10}$ Diabetes may cause changes in the collagen metabolism, gingival crevicular fluid, host response and the tissue micro flora. Inflammatory mediators like interleukin (IL)-1, IL-6 and tumor necrosis factor (TNF) alpha are formed by inflamed periodontal tissues which change the glycemic control thus affecting the glucose and lipid metabolism. ${ }^{10}$

Numerous studies have been conducted which show that very few patients with diabetes visit dentists for regular check-ups to evaluate their periodontal health status and are not aware of the knowledge of the oral health maintenance. There were few studies conducted on the assessment of the behavior and attitude of doctors towards the treatment of patients having diabetes. It was found out that very few physicians convey with the patient's dentists regarding their diabetes status and oral condition. ${ }^{11}$

Allen conducted a study in which he assessed the knowledge of diabetic patients about periodontal diseases and found that they had a very low awareness of this relationship, as compared to increased knowledge for the increased risk of eye diseases, heart disease, kidney disease and circulatory problems. ${ }^{12}$ Despite the role of oral health care in systemic health, it is an aspect that is often neglected..$^{13}$ It is recommended that physicians should integrate education into the management regimen of their diabetic patients about periodontal disease and its risk factors. There should be a focus on referral of diabetic patients to dental care professionals for thorough dental evaluation. ${ }^{14}$

Thus, it is necessary for medical practitioners to have basic dental education to evaluate symptoms and diagnose dental diseases among patients, to deliver emergency dental treatment when needed or to recommend these patients to maintain good oral hygiene. ${ }^{15}$ Dental students have adequate knowledge about periodontal disease but limited studies are available which reveal the knowledge of medical students about periodontal disease as a complication of diabetes mellitus in Pakistan. Therefore; the rationale of this study was to find out the knowledge regarding the relationship between diabetes mellitus and oral health among medical students. This study would be beneficial in enlightening the medical students about periodontal disease and its serious short term and long term complications. The aim of this study was to evaluate the awareness and knowledge of periodontal disease among medical students of Bahria University Medical and Dental College (BUMDC) while treating diabetic patients.

\section{METHODOLOGY:}

A cross sectional questionnaire based study was conducted in Bahria University Medical and Dental College (BUMDC) Karachi from august 2018 to December 2018.Sample size was calculated as 384 on the prevalence of $50 \%$. A selfadministered questionnaire was distributed among the subjects through convenience sample technique and written consent was obtained from each participant before filling the forms. This study included participants who are currently studying in $3^{\text {rd }}, 4^{\text {th }}$ and final year bachelor of medicine and bachelor of surgery (MBBS) in BUMDC Karachi. Students who failed to give consent were excluded. Ethical clearance certificate was obtained from ethical review committee of Bahria University Medical and Dental College (BUMDC) Karachi Pakistan numbered ERC 63/2018.

A survey comprising of 15 questions was used to assess the knowledge among medical students regarding periodontal disease in diabetic patients. Questionnaire was divided into two parts, in the first part, demographic details and year of study were asked, in the second part, questions regarding diabetes mellitus and its complications were included. The questionnaire assessed the knowledge of medical students regarding periodontal disease in diabetic patients through following questions (1) ADA approved fasting blood glucose test level (2) most common oral micro vascular complications of diabetes(3) knowledge of Periodontitis(4) clinical manifestations in Periodontitis(5) most commonly found periodontal manifestation among uncontrolled diabetic individuals(6) estimate your knowledge about periodontitis and its relationship with systemic disease.Data analysis was done using SPSS Version 23.

\section{RESULTS:}

Among 384 participants, 142 were males and 242 females. 128 participants were from $3^{\text {rd }}$ year, 129 from $4^{\text {th }}$ and 127 from final year. All the participants successfully completed the questionnaire so the response rate was $100 \%$ in this study. According to the results shown in table 2, this study depicts that only $13.3 \%$ of medical students always ask diabetic patients if they have ever been diagnosed with periodontal disease.

A majority of respondents i.e. $64.1 \%$ were aware of periodontal disease in diabetic patients whereas only 19.5 $\%$ individual had knowledge of periodontitis.

Among the entire population of medical students; $44 \%$ could 


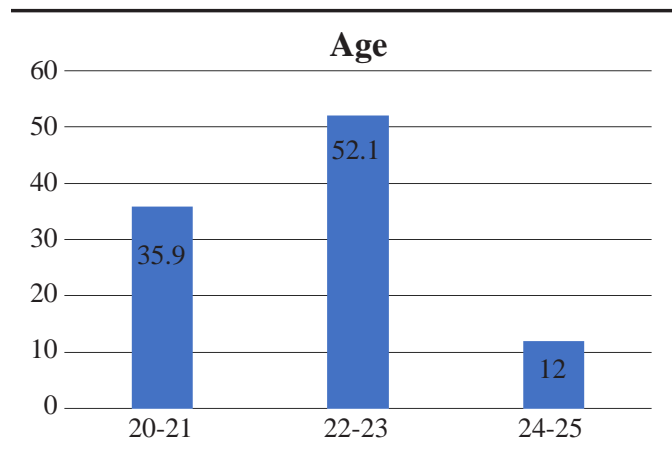

Gender

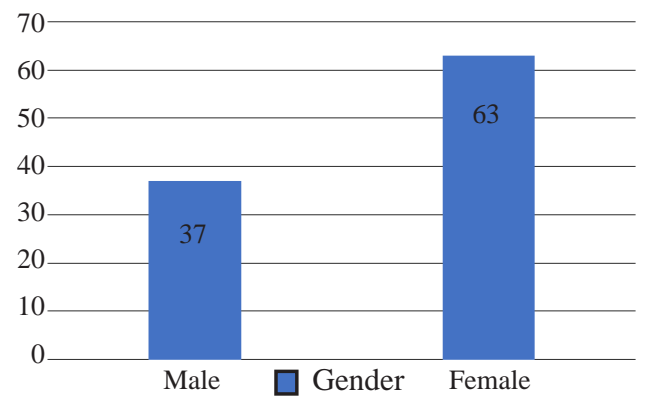

not specify clinical manifestations in periodontitis and only $48.4 \%$ participants could state the periodontal manifestations present in diabetic mellitus.

About $33.6 \%$ of the participants thought that they have moderate to good knowledge about periodontitis and its relationship with systemic diseases like diabetes mellitus. $34.1 \%$ of the individuals never referred while $19.3 \%$ of the individuals always refer their patients for evaluation to a dentist.

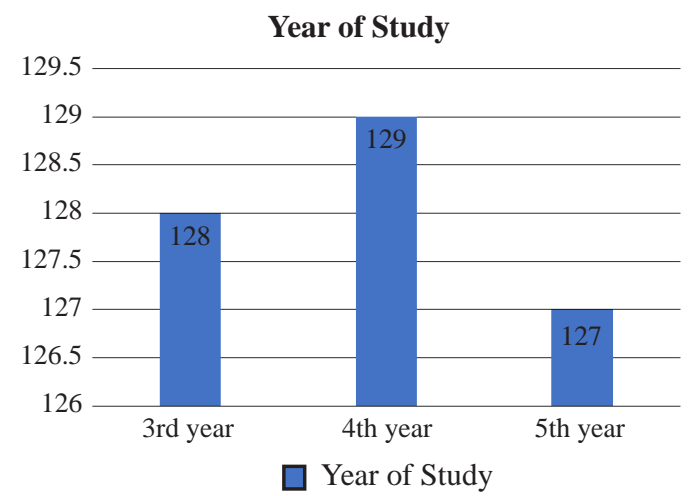

Table 1. Knowledge Parameters of Periodontal Disease in Diabetic patients among $3^{\text {rd }}, 4^{\text {th }}$ and $5^{\text {th }}$ year MBBS Students.

\begin{tabular}{|c|c|c|c|c|c|}
\hline Parameters & Options & 3rd Year & 4th Year & 5th Year & P-value \\
\hline \multirow{4}{*}{$\begin{array}{l}\text { Normal range of fasting blood } \\
\text { glucose level }\end{array}$} & $50-69 \mathrm{mg} / \mathrm{dl}$ & $2(1.6 \%)$ & $8(6.2 \%)$ & $1(0.8 \%)$ & \multirow{4}{*}{0.000} \\
\hline & $70-99 \mathrm{mg} / \mathrm{dl}$ & $95(74.2 \%)$ & $79(61.2 \%)$ & $60(47.2 \%)$ & \\
\hline & $100-125 \mathrm{mg} / \mathrm{dl}$ & $26(20.3 \%)$ & $35(27.1 \%)$ & $60(47.2 \%)$ & \\
\hline & $>126 \mathrm{mg} / \mathrm{dl}$ & $5(3.9 \%)$ & $7(5.4 \%)$ & $6(4.7 \%)$ & \\
\hline \multirow{4}{*}{$\begin{array}{l}\text { Fasting blood glucose test level } \\
\text { in diabetes }\end{array}$} & $50-69 \mathrm{mg} / \mathrm{dl}$ & $1(0.8 \%)$ & $9(7.0 \%)$ & $3(2.4 \%)$ & \multirow{4}{*}{0.005} \\
\hline & $70-99 \mathrm{mg} / \mathrm{dl}$ & $8(6.3 \%)$ & $10(7.8 \%)$ & $5(3.9 \%)$ & \\
\hline & $100-125 \mathrm{mg} / \mathrm{dl}$ & $28(21.9 \%)$ & $36(27.9 \%)$ & $19(13 \%)$ & \\
\hline & $>126 \mathrm{mg} / \mathrm{dl}$ & $91(71.1 \%)$ & $74(57.4 \%)$ & $100(78.7 \%)$ & \\
\hline \multirow{4}{*}{$\begin{array}{l}\text { Most Common oral } \\
\text { complications in diabetes } \\
\text { mellitus }\end{array}$} & Xerostomia & $38(29.7 \%)$ & $64(49.6 \%)$ & $50(39.4 \%)$ & \multirow{4}{*}{0.014} \\
\hline & Gingivitis & $72(56.3 \%)$ & $42(32.6 \%)$ & $55(43.3 \%)$ & \\
\hline & Leukoplakia & $8(6.3 \%)$ & $11(8.5 \%)$ & $8(6.3 \%)$ & \\
\hline & Gingival enlargement & $10(7.8 \%)$ & $12(9.3 \%)$ & $14(11.0 \%)$ & \\
\hline \multirow{4}{*}{ What is Periodontitis? } & Inflammation of Enamel & $22(17.2 \%)$ & $47(36.4 \%)$ & $31(24.4 \%)$ & \multirow{4}{*}{0.000} \\
\hline & Inflammation of Dentin & $39(30.5 \%)$ & $21(16.3 \%)$ & $30(23.6 \%)$ & \\
\hline & Inflammation of gingiva & $55(43.0 \%)$ & $37(28.7 \%)$ & $27(21.3 \%)$ & \\
\hline & $\begin{array}{l}\text { Inflammation of PDL, } \\
\text { Cementum \& Bone }\end{array}$ & $12(9.4 \%)$ & $24(18.6 \%)$ & $39(30.7 \%)$ & \\
\hline \multirow{4}{*}{$\begin{array}{l}\text { Rank of Periodontitis in } \\
\text { complication of diabetes } \\
\text { mellitus. }\end{array}$} & $1 \mathrm{st}$ & $26(20.3 \%)$ & $23(17.8 \%)$ & $15(11.8 \%)$ & \multirow{4}{*}{0.003} \\
\hline & 2 nd & $27(21.1 \%)$ & $26(20.2 \%)$ & $26(20.2 \%)$ & \\
\hline & $3 \mathrm{rd}$ & $40(31.3 \%)$ & $38(29.5 \%)$ & $21(16.5 \%)$ & \\
\hline & 6th & $35(27.3 \%)$ & $42(32.6 \%)$ & $65(512 \%)$ & \\
\hline \multirow{4}{*}{$\begin{array}{l}\text { Destruction of periodontal } \\
\text { structures in poorly controlled } \\
\text { diabetic }\end{array}$} & Increased collagenase activity & $19(14.8 \%)$ & $20(15.5 \%)$ & $21(16.5 \%)$ & \multirow{4}{*}{0.263} \\
\hline & Decreased collagen synthesis & $35(27.3 \%)$ & $36(27.9 \%)$ & $28(22.0 \%)$ & \\
\hline & Decreased collagenase activity & $13(10.2 \%)$ & $16(12.4 \%)$ & $6(4.7 \%)$ & \\
\hline & Both a \& b & $61(47.7 \%)$ & $57(44.2 \%)$ & $72(56.7 \%)$ & \\
\hline \multirow{3}{*}{$\begin{array}{l}\text { Most common periodontal } \\
\text { manifestation in diabetes }\end{array}$} & Periodontal abscess & $31(24.2 \%)$ & $26(20.2 \%)$ & $28(22.0 \%)$ & \multirow{3}{*}{0.024} \\
\hline & Bleeding gums & $72(56.2 \%)$ & $58(44.9 \%)$ & $56(44.0 \%)$ & \\
\hline & Ulcers & $25(19.5 \%)$ & $45(34.9 \%)$ & $43(33.85 \%)$ & \\
\hline
\end{tabular}


Awareness Of Medical Students Regarding Periodontal Disease In Diabetic Patients In A Private Dental College of Karachi

Table 2. Awareness Parameters of periodontal disease in diabetic patients among $3^{\text {rd }}, 4^{\text {th }}$ and $5^{\text {th }}$ year MBBS Students.

\begin{tabular}{|c|c|c|c|c|c|}
\hline Parameters & OPTIONS & $3^{\mathrm{RD}}$ YEAR & $4^{\mathrm{TH}}$ YEAR & $5^{\mathrm{TH}}$ YEAR & P-value \\
\hline \multirow{2}{*}{$\begin{array}{l}\text { Awareness of complications } \\
\text { of diabetes }\end{array}$} & Yes & $118(92.2 \%)$ & $117(90.7 \%)$ & $118(92.9 \%)$ & \multirow{2}{*}{0.090} \\
\hline & No & $10(7.8 \%)$ & $12(9.3 \%)$ & $9(7.1 \%)$ & \\
\hline \multirow{2}{*}{$\begin{array}{l}\text { Awareness of periodontal } \\
\text { disease in diabetics? }\end{array}$} & Yes & $77(60.2 \%)$ & $90(69.8 \%)$ & $79(62.2 \%)$ & \multirow{2}{*}{0.005} \\
\hline & No & $51(39.8 \%)$ & $39(30.2 \%)$ & $48(37.7 \%)$ & \\
\hline \multirow{3}{*}{$\begin{array}{l}\text { Ask patients about } \\
\text { periodontal disease }\end{array}$} & Never & $69(53.9 \%)$ & $62(48.1 \%)$ & $82(64.6 \%)$ & \multirow{3}{*}{0.020} \\
\hline & Often & $37(28.9 \%)$ & $52(40.3 \%)$ & $31(24.4 \%)$ & \\
\hline & Always & $22(17.2 \%)$ & $15(11.6 \%)$ & $14(11.0 \%)$ & \\
\hline \multirow{4}{*}{$\begin{array}{l}\text { Clinical manifestations in } \\
\text { Periodontitis }\end{array}$} & Bleeding gums & $53(41.4 \%)$ & $46(35.7 \%)$ & $24(18.9 \%)$ & \multirow{4}{*}{0.002} \\
\hline & Mobile teeth & $3(2.3 \%)$ & $5(3.9 \%)$ & $10(7.9 \%)$ & \\
\hline & Gingival recession & $6(4.7 \%)$ & $13(10.1 \%)$ & $9(7.1 \%)$ & \\
\hline & All of the above & $66(51.6 \%)$ & $65(50.4 \%)$ & $84(66.1 \%)$ & \\
\hline \multirow{4}{*}{$\begin{array}{l}\text { Advise to diabetic patients } \\
\text { who have or are at risk for } \\
\text { periodontal disease }\end{array}$} & $\begin{array}{l}\text { Encouraged to visit a dentist at } \\
\text { least once a year }\end{array}$ & $73(57.0 \%)$ & $76(58.9 \%)$ & $81(63.8 \%)$ & \multirow{4}{*}{0.459} \\
\hline & $\begin{array}{l}\text { Advised to follow a strict a diet } \\
\text { regimen }\end{array}$ & $36(28.1 \%)$ & $30(23.3 \%)$ & $33(26.0 \%)$ & \\
\hline & $\begin{array}{l}\text { Advised to increase the drug } \\
\text { dosage }\end{array}$ & $9(7.0 \%)$ & $15(11.6 \%)$ & $9(7.1 \%)$ & \\
\hline & Advised to reduce weight & $10(7.8 \%)$ & $8(6.2 \%)$ & $4(3.1 \%)$ & \\
\hline \multirow{3}{*}{$\begin{array}{l}\text { Knowledge about periodontal } \\
\text { disease and its relationship } \\
\text { with systemic disease }\end{array}$} & Limited & $86(67.2 \%)$ & $90(69.8 \%)$ & $79(62.2 \%)$ & \multirow{3}{*}{0.004} \\
\hline & Moderate & $35(27.3 \%)$ & $18(14.0 \%)$ & $36(28.3 \%)$ & \\
\hline & Good & $7(5.5 \%)$ & $21(16.3 \%)$ & $12(9.4 \%)$ & \\
\hline \multirow{4}{*}{$\begin{array}{l}\text { Role as a physician for } \\
\text { evaluation of periodontal }\end{array}$} & Strongly disagree & $10(7.8 \%)$ & $30(23.3 \%)$ & $10(7.9 \%)$ & \multirow{4}{*}{0.000} \\
\hline & Disagree & $16(12.5 \%)$ & $22(17.1 \%)$ & $26(20.5 \%)$ & \\
\hline & Agree & $86(67.2 \%)$ & $73(56.6 \%)$ & $82(64.6 \%)$ & \\
\hline & Strongly agree & $16(12.5 \%)$ & $4(3.1 \%)$ & $9(7.1 \%)$ & \\
\hline
\end{tabular}

\section{DISCUSSION:}

This study was conducted to evaluate the knowledge and awareness of periodontal disease commonly present in diabetic patients among medical students. Diabetes has been linked to chronic periodontitis. In an epidemiologic study conducted in the United States, Periodontitis is 2.9 times more common in individuals with poorly controlled diabetes as compared to non-diabetic individuals. ${ }^{16}$ A study reported that it's a bidirectional relationship between DM and periodontal disease (PD). It's a relationship in which Periodontal Disease can effect glycemic control levels and uncontrolled Diabetes can aggravate Periodontal Disease. ${ }^{17}$ Generally only dental hygienists and Dentists have been educated regarding the oral disease and its systemic association..$^{18}$ However there are quite less studies about education of medical practitioners regarding oral-systemic connection related to periodontal disease and its systemic complication. ${ }^{19}$

In our study only $19.5 \%$ of the participants had a knowledge about periodontitis which was significantly lower than the study conducted by Roshni Jaiswal which was found to be
$43.33 \% .{ }^{20}$ According to our study $64.1 \%$ of the participants were aware that diabetic individuals are prone to periodontal disease which was comparable to $68 \%$ of Indian population. ${ }^{20}$ So overall medical students have limited knowledge of diabetes and its oral manifestations. A study by al Khabbaz et al, showed that only half of all study participants believed that diabetic patients were more vulnerable to tooth loss whereas in our study almost $60.7 \%$ individuals believed that diabetic patients were more vulnerable to tooth loss because of periodontal diseases than non-diabetic individuals. ${ }^{11}$

There are various studies which highlight the association of systemic disease with periodontal condition. These studies recommended that controlling periodontal and gingival disease may be significant in reducing other systemic inflammatory conditions, thus preventing or controlling diabetes mellitus, cardiovascular diseases and other systemic diseases. ${ }^{21,22} \mathrm{~A}$ study conducted in North Carolina concluded that majority of the endocrinologists and internists have very limited knowledge about the association of diabetes mellitus with periodontal disease. ${ }^{23} \mathrm{~A}$ study conducted byBahammam MA, showed that the patients with diabetes 
lack basic knowledge about the association between oral health and diabetes. ${ }^{24} \mathrm{As}$ the number of patients having oral complications of diabetes mellitus and other systemic diseases is increasing with time so it is important to incorporate medical-dental collaboration and inter-professional education to manage the rising number of patients. Physicians need to show more interest and get more involved in promotion of oral health. Moreover, incorporation of oral health education in the curriculum of medical students is necessary ${ }^{25}$ General physicians should get a proper education and knowledge before they can take up a broader role in the early diagnosis of oral diseases. ${ }^{26}$

Failure of examination of the oral cavity which includes teeth and its supporting structures by physician has been reported. ${ }^{27}$ So it should be encouraged to do routine oral examination of patients with uncontrolled diabetes who are at higher risk for developing periodontal disease. When physicians are examining a diabetic patients, it is vitally important to include examination of oral cavity as it is important for the treatment of Periodontal disease and diabetes mellitis. ${ }^{28}$ Medical practitioners should take certain regulatory steps which includes: inquiring diabetic individuals about their oral hygiene, specifically bad breath, any sign of inflammation, altered taste sensation(Dysgeusia) or any other oral symptoms; also questioning regarding last visit to a dentist and reminding diabetic individuals that they need to have dental examination every 6 months as recommended by American Dental Association (ADA).Diabetic patients should be presented with a personalized dental plan which can be used to inhibit and control periodontitis. ${ }^{29}$

A study conducted among medical students in Australia revealed that there's generally positive approach towards the significance of oral health trainings. But they had overall less understanding of dental caries, oral-systemic connections, and oral health inconsistency during undergraduate years. ${ }^{19}$ The strength of this study was the huge sample size and the intended topic of the study. Among the limitations the single centered study but the results can be generalized to the entire population due to diabetic prevalence in Pakistan. .It is recommended that during medical school years, students obtain less than two hours of training on oral health. More studies are required to assess the impact of dental health referrals and patient's educational interventions. There should be interdisciplinary approach is required between dental and medical professionals to provide holistic care to the diabetic individuals who are at increased risk for periodontal disease and insure timely treatment of the individuals. It is necessary to implement learning approaches in the curriculum for medical and dental students to extend professional education and their association to educate dentists and physicians for prevention and management of diabetic patients with periodontal disease.

\section{CONCLUSION:}

It is concluded from the study that medical students have very limited knowledge regarding periodontal disease and its association with diabetes mellitus. Very few medical students were informed about referring the diabetic patients to the dental surgeon.

\section{REFERENCES}

1. Kamran S, Moradian H, Bakhsh EY. Comparison of the Mean DMF Index in Type I Diabetic and Healthy Children. Journal of Dentistry. 2019;20(1):61.

2. American Diabetes Association. 2. Classification and diagnosis of diabetes. Diabetes care. 2017; 40(Supplement 1): S11-24.

3. World Health Organization. Global report on diabetes. World Health Organization; 2016.

4. Cho NH, Shaw JE, Karuranga S, Huang Y, da Rocha Fernandes JD, Ohlrogge AW, Malanda B. IDF Diabetes Atlas: global estimates of diabetes prevalence for 2017 and projections for 2045. Diabetes research and clinical practice. 2018;138:27181.

5. Hussain A, Ali I. Diabetes mellitus in Pakistan: A major public health concern. Archives of Pharmacy Practice. 2016;7(1):30.

6. Salman S, Khan K, Salman F, Hameed M. Effect of nonsurgical periodontal treatment on glycemic control among type 2 diabetes mellitus patients with periodontitis. Journal of Ayub Medical College Abbottabad. 2016;28(4):742-5.

7. Varela-Centelles P, Diz-Iglesias P, Estany-Gestal A, Blanco Hortas A, Bugarín-González R, Seoane-Romero JM, Blanco J. Periodontal awareness and what it actually means: A crosssectional study. Oral diseases. 2019;25(3):831-8.

8. Kinane DF, Stathopoulou PG, Papapanou PN. Periodontal diseases. Nature Reviews Disease Primers. 2017; 22(3):17038.

9. Verhulst MJ, Loos BG, Gerdes VE, Teeuw WJ. Evaluating all potential oral complications of diabetes mellitus. Front. Endocrinol. 10: 56. https://doi.org/10.3389/fendo.2019.00056

10. Baranowski MJ, Wójtowicz A, Wysokiñska-Miszczuk J, Klempka J, Kubiszyn M. Diabetes in dental practice-review of literature. Journal of Education, Health and Sport. 2019;9(2):264-74.

11. Al-Khabbaz AK, Al-Shammari KF, Al-Saleh NA. Knowledge about the association between periodontal diseases and diabetes mellitus: contrasting dentists and physicians. Journal of periodontology. 2011; 82(3): 360-6.

12. Allen EM, Ziada HM, O'halloran D, Clerehugh V, Allen PF. Attitudes, awareness and oral health-related quality of life in patients with diabetes. Journal of oral rehabilitation. 2008; 35(3): 218-23.

13. Oyetola EO, Oyewole T, Adedigba M, Aregbesola ST, Umezudike K, Adewale A. Knowledge and awareness of medical doctors, medical students and nurses about dentistry in Nigeria. Pan African Medical Journal. doi: 10.11604/pamj. 2016.23.172.7696

14. Fatima G, Akhtar MJ, Naveed N, Ahmd M, Tariq M, Khawaja AR. Diabetic Patients And Periodontitis: A Study. Pakistan Oral \& Dental Journal. 20170;37(2):290-3.

15. Ahmad MS, Abuzar MA, Razak IA, Rahman SA, Borromeo GL. Educating medical students in oral health care: current curriculum and future needs of institutions in Malaysia and Australia. European Journal of Dental Education. 2017;21(4) :e29-38. 
16. Knight ET, Liu J, Seymour GJ, Faggion Jr CM, Cullinan MP. Risk factors that may modify the innate and adaptive immune responses in periodontal diseases. Periodontology 2000. 2016;71(1):22-51.

17. Bascones-Martinez A, Gonzalez-Febles J, Sanz-Esporrin J. Diabetes and periodontal disease. Review of the literature. Am J Dent. 2014;27(2):63-7.

18. Sede MA, Ehizele AO. Oral diseases and diabetes: Nigerian medical and dental caregivers' perspective. Annals of African medicine. 2015;14(4):193.

19. Abbott B, Zybutz C, Scott KM, Eberhard J, Widmer R. A review of the hours dedicated to oral health education in medical programmes across Australia. Internal medicine journal. 2018;48(9):1035-40.

20. Jaiswal R, Shenoy N, Thomas B. Extent of awareness regarding periodontal disease in diabetic patients among medical interns. Nitte University Journal of Health Science. 2015;5(4):17.

21. Hsu YT, Nair M, Angelov N, Lalla E, Lee CT. Impact of diabetes on clinical periodontal outcomes following nonsurgical periodontal therapy. Journal of clinical periodontology. 2019;46(2):206-17.

22. Roy M, Gastaldi G, Courvoisier DS, Mombelli A, Giannopoulou C. Periodontal health in a cohort of subjects with type 1 diabetes mellitus. Clinical and Experimental Dental Research. 201;5(3):243-9.

23. Owens JB, Wilder RS, Southerland JH, Buse JB, Malone RM. North Carolina internists' and endocrinologists' knowledge, opinions, and behaviors regarding periodontal disease and diabetes: need and opportunity for interprofessional education. Journal of Dental Education. 2011;75(3):329-38.
24. Bahammam MA. Periodontal health and diabetes awareness among Saudi diabetes patients. Patient preference and adherence. 2015;9:225-33.

25. Mohebbi SZ, Rabiei S, Yazdani R, Nieminen P, Virtanen JI. Evaluation of an educational intervention in oral health for primary care physicians: a cluster randomized controlled study. BMC oral health. 2018;18(1):218. doi: 10.1186/s12903018-0676-2

26. Dana R, Torneck CD, Iglar K, Lighvan NL, Quiñonez C, Azarpazhooh A. Knowledge and Practices of Family and Emergency Physicians in Managing Nontraumatic Dental Conditions: A Case-based Survey. Journal of endodontics. 2019;45(3):263-71.

27. Parker JL. Interdisciplinary Health Professions Faculty's Lived Experiences with Oral Health Curricular Integration: An Interpretative Phenomenological Analysis (Doctoral dissertation, Northeastern University).

28. Horikawa Y, Suzuki A, Enya M, Hashimoto KI, Nishida S, Kobayashi R, et. al. Periodontal Disease May be Associated With the Occurrence of Diabetic Retinopathy: A Subgroup Analysis of The Survey of the Diabetes Coordination Notebook in Gifu. Experimental and Clinical Endocrinology \& Diabetes. 2019 Apr 11. doi: 10.1055/a-0879-1890.

29. Al-Habashneh R, Barghout N, Humbert L, Khader Y, Alwaeli $H$. Diabetes and oral health: doctors' knowledge, perception and practices. Journal of evaluation in clinical practice. 2010;16(5):976-80. 